\title{
Homozygous deletion of TNFRSF4, TP73, PPAP2B and DPYD at $1 p$ and PDCD5 at $19 q$ identified by multiplex ligation-dependent probe amplification (MLPA) analysis in pediatric anaplastic glioma with questionable oligodendroglial component
}

\author{
Miguel Torres-Martín , Carolina Peña-Granero ${ }^{1}$, Fernando Carceller², Manuel Gutiérrez ${ }^{3}$, Rommel R Burbano ${ }^{4}$, \\ Giovanny R Pinto ${ }^{5}$, Javier S Castresana ${ }^{6}$, Bárbara Melendez ${ }^{7}$ and Juan A Rey ${ }^{1 *}$
}

\begin{abstract}
Background: Pediatric oligodendrogliomas are rare and appear to show a different molecular profile from adult tumors. Some gliomas display allelic losses at $1 p / 19 q$ in pediatric patients, although less frequently than in adult patients, but this is rare in tumors with an oligodendroglial component. The molecular basis of this genomic abnormality is unknown in pediatric gliomas, but it represents a relatively common finding in pediatric oligodendroglioma-like neoplasms with leptomeningeal dissemination.

Results: Multiplex ligation-dependent probe amplification (MLPA) analysis using SALSA P088-B1 for the analysis of the $1 \mathrm{p} / 19 \mathrm{q}$ allelic constitution in a pediatric anaplastic (oligodendro)-glioma showed homozygous co-deletion for markers: TNFRSF4 (located at 1p36.33), TP73 (1p36.32), PPAP2B (1pter-p22.1), DPYD (1p21.3), and PDCD5 (19q13.12), and hemizygous deletion of BAX (19q13.3-q13.4). No sequence changes for R132 and R172 of the IDH1/2 genes were identified.

Conclusions: The molecular findings in this pediatric anaplastic glioma do not allow for a clearly definitive pathological diagnosis. However, the findings provide data on a number of $1 \mathrm{p} / 19 \mathrm{q}$ genomic regions that, because of homozygotic deletion, might be the location of genes that are important for the development and clinical evolution of some malignant gliomas in children.
\end{abstract}

Keywords: Pediatric anaplastic glioma, Oligodendroglioma, Homozygous deletion 1p/19q, MLPA

\section{Background}

According to Hargrave D [1] high grade gliomas in pediatric oncology generally group grade III and IV tumors with astrocytic or oligodendroglial nature, and include anaplastic astrocytomas (grade III), glioblastomas (grade IV) and anaplastic tumors (grade III) that have a major oligodendroglial component, i.e., pure oligodendrogliomas and mixed oligoastrocytomas. Although malignant astrocytomas represent

\footnotetext{
* Correspondence: jreyh@salud.madrid.org

1 Molecular Neuro-oncogenetics Laboratory, Research Unit-Unidad de Investigación, Hospital Universitario La Paz, Paseo de la Castellana 261, 28046 Madrid, Spain

Full list of author information is available at the end of the article
}

approximately $8 \%-10 \%$ of all pediatric CNS tumors, most arising in the supratentorial region, high-grade oligodendrogliomas in children are rare [2]. An incidence of $6 \%$ has been reported for oligodendroglial tumors (including pure oligodendrogliomas and mixed oligo-astrocytomas) in children aged $0-14$ years [2]. The histology of these neoplasms with oligodendroglial component is classical and has been described as having a "fried-egg" appearance with "chicken-wire" vasculature. Anaplastic variants are primarily based on the presence of mitotic activity, microvascularization and necrosis, while anaplastic astrocytomas are diffusely infiltrating tumors with increased cellularity, distinct nuclear atypia and 
marked mitotic activity $[3,4]$. The molecular biology of adult malignant gliomas is now well defined for tumors with either astrocytic or oligodendroglial characteristics. Both types of gliomas are very complex and genetically heterogeneous, with multiple alterations in critical pathways, primarily alterations of $M G M T$ (methylation), $I D H 1 / 2$ (mutation), 1p/19q co-deletion, EGFR and PI3K pathway variations, and $p 53$ or $R b$ pathway mutation [5,6]. Among the pediatric malignant gliomas, EGFR gene amplification appears to occur less frequently than in tumors from adult patients, and only $2 \%$ have the EGFRvIII variant. In contrast, it appears that PDGFRA and PDGFRB are more commonly affected in high-grade pediatric gliomas $[1,7,8]$. Recently, whole genome sequencing in low-grade pediatric gliomas has identified multiple genetic alterations involving several genes such as BRAF, RAF1, FGFR1, MYB and MYBL1 $[9,10]$. Copy number alteration analysis has demonstrated gains of chromosomes 7, 8 and $5 \mathrm{q}$ and loss of $1 \mathrm{p}$ [10]. Up to 6 significantly recurrent regions of focal deletion have been identified: 9p21.3 (and the adjacent region), 6q26, 10q21.3, 8p22 and 13q31.3, where multiple genes with functions related to cancer development are located [10]. In this report we describe the partial concurrent homozygous deletion at $1 \mathrm{p} / 19 \mathrm{q}$ in an anaplastic glioma (or oligodendroglioma) that took place in a 6-year-old boy. This event might provide insights on a subgroup of pediatric (oligodendro)-gliomas with $1 \mathrm{p} / 19 \mathrm{q}$ involvement.

\section{Case presentation}

\section{Medical history and examination}

A 6-year-old boy was admitted to the La Paz Hospital for complaining of tremors in the left arm. The patient had a history of occasional holocranial headaches and vomiting over the last 2 months and was experiencing thalamic pain. There were no memory or behavioral changes or performance impairment, and the examination revealed no papilloedema. The patient had a postural tremor $(6-8 \mathrm{~Hz})$ in the outstretched left arm, which was more prominent in the distal muscle groups. The tremor was slightly accentuated when moving the arm. The tremors ceased when the limb was at rest and when the patient was asleep. The patient had no nystagmus or gait ataxia, and his speech was normal. His osteo-cutaneous reflexes were slightly enhanced on the left side, but he had no sensory abnormalities. The examination revealed a slight left hemiparesis. The patient's left hand was closed due to dystonia, and his left foot presented dystonia when walking.

A brain CT scan revealed obstructive hydrocephalus caused by a hypo-dense right thalamic and upper brainstem tumor, which was producing a mass effect on the basal ganglia and a shift in the lateral ventricle. T1-weighted 3 T-MR imaging showed a large heterogeneous solid, cystic tumor arising from the right thalamus and extending to the brainstem. An MR-imaging study performed with gadolinium (Gd) contrast showed a ring-enhancing pattern. Diffusion-tensor imaging was conducted to locate the posterior limb of the internal capsule (PLIC) in the preoperative MR (Figure 1A). The laterally displaced PLIC was even more posterior than expected, which made an anterior approach the most appropriate.

\section{Surgery}

The child underwent a right frontal craniotomy, and a trans-cortical frontal approach to the right lateral ventricle was performed for a gross total resection (GTR) of the tumor. This procedure was accomplished using a micro-neurosurgical technique. At the completion of the resection, an endoscopic third ventriculostomy was performed. An intraoperative pathological examination identified an anaplastic (possibly astrocytic) glioma.

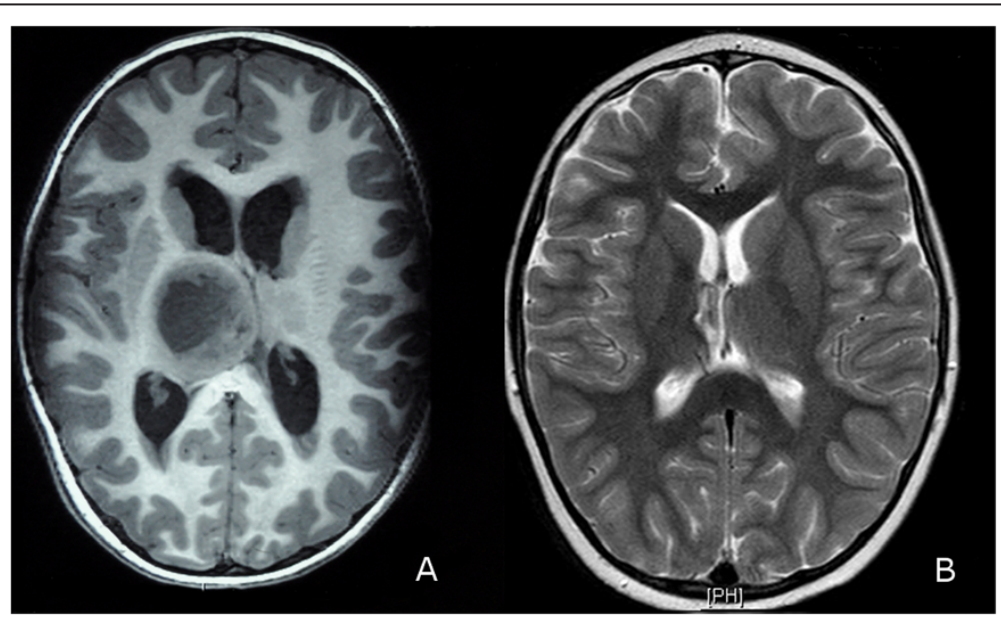

Figure 1 MRI of pediatric glioma. (A) MRI shows a large right thalamic tumor compressing the third ventricle. (B) MRI control 9 months later. 

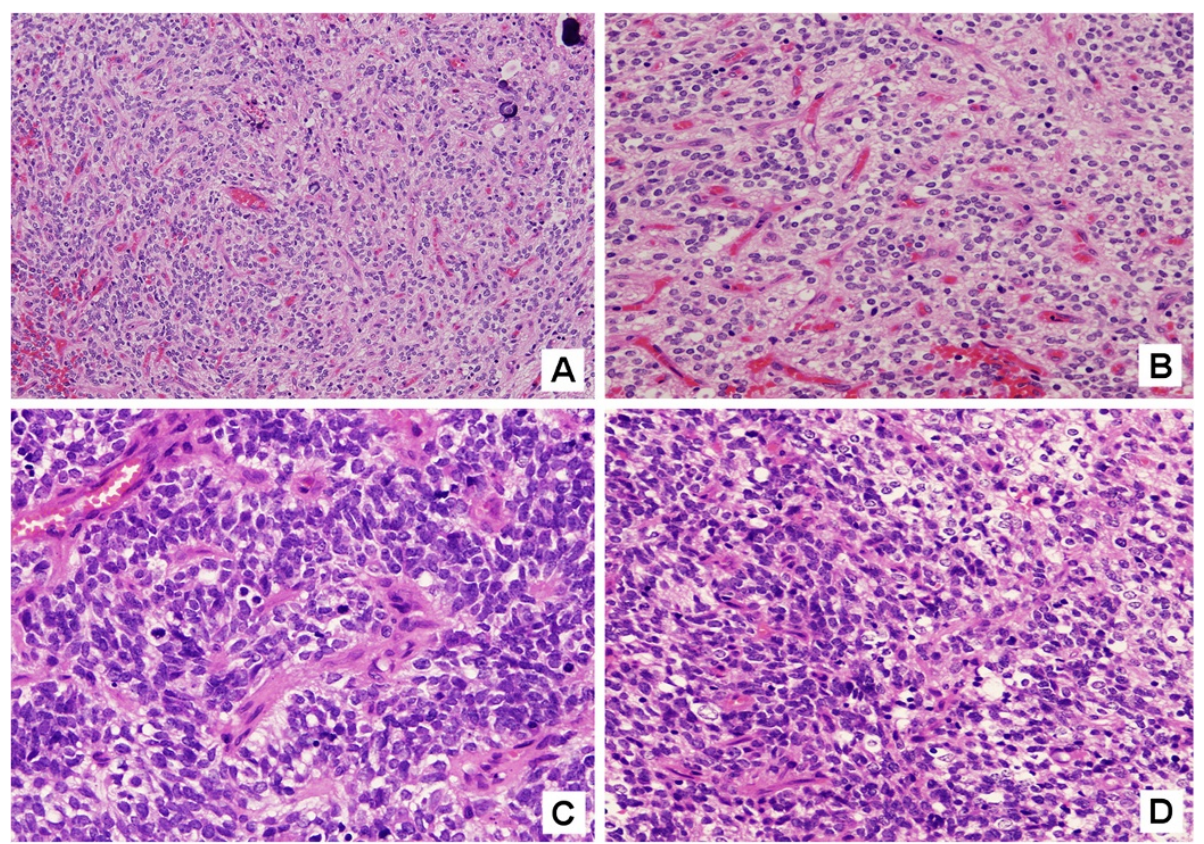

Figure 2 Histopathological features of the pediatric glioma reported. (A) Microcalcifications. (B) A prominent micro-vascular stroma presenting branching capillaries with endothelial tumefaction can be observed. (C) Anaplastic aspect with high nuclear to cytoplasmic ratio and mitosis was present. (D) Intermingled "egg-fried" cells can be observed in a number of anaplastic foci.
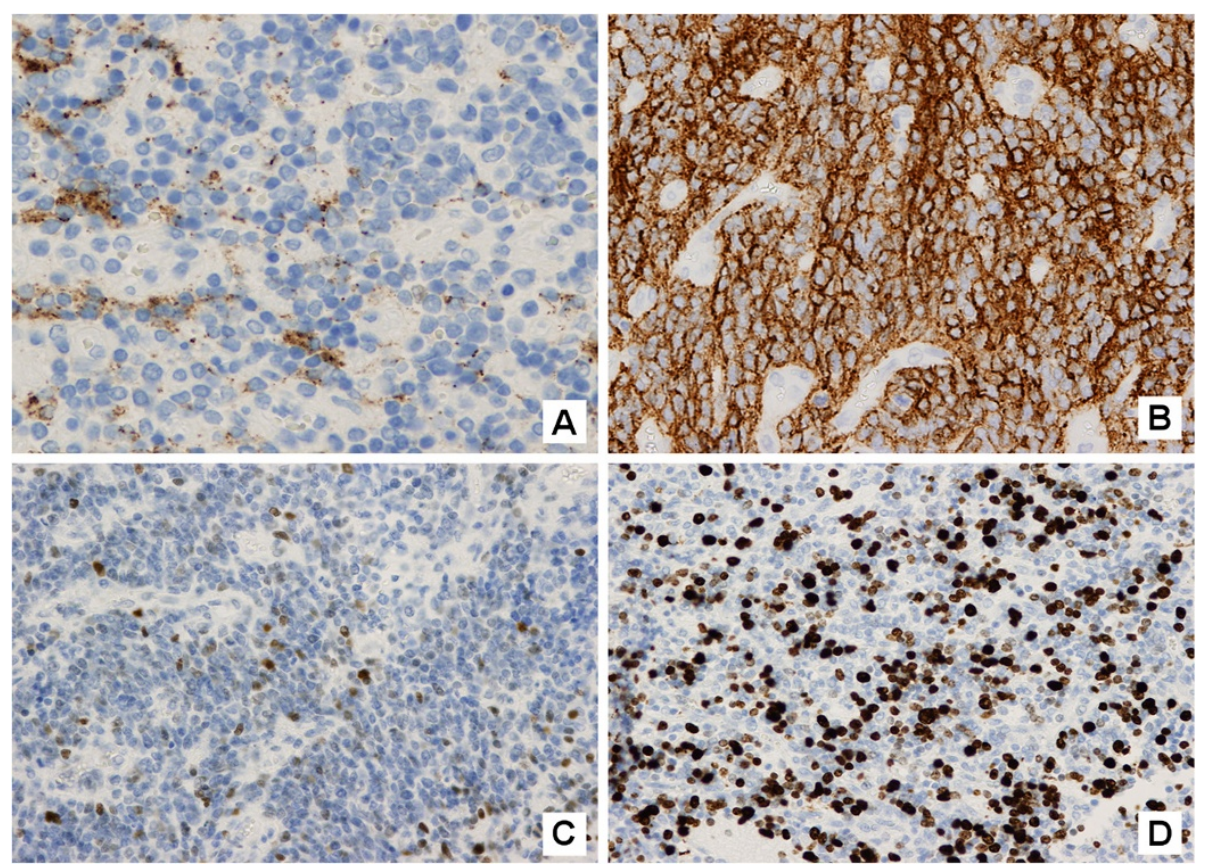

Figure 3 Tumor immunoreactivity. (A) GFAP immunoreactivity was variable whereas Synaptophysin was negative. (B) Cytoplasmic

immunoreactivity for Vimentin and CD57 (HNK-1) were positive. (C) Nuclear p53 was positive in 15\%-20\% of cells. (D) Growth fraction (ki 67) was approximately $30 \%$ 
Table 1 Summary of run by Coffalyser

\begin{tabular}{|c|c|c|c|c|c|}
\hline Gene & Markers & P Run1 & P Run2 & PC Run1 & PC Run2 \\
\hline NOTCH2 & $01 \mathrm{p} 12$ & 0.9 & 0.82 & 0.57 & 0.55 \\
\hline TNFRSF4 & 01 p36 & 0.32 & 0.14 & 0.52 & 0.49 \\
\hline GNB1 & $01 p 36.33$ & 0.88 & 0.84 & 0.43 & 0.45 \\
\hline TNFRSF14 & $01 p 36.32$ & 1.17 & 0.9 & 0.48 & 0.48 \\
\hline TP73 & $01 p 36.3$ & 0.14 & 0.11 & 0.61 & 0.57 \\
\hline PARKT & $01 p 36.33-p 36.12$ & 1 & 0.82 & 0.59 & 0.57 \\
\hline MFN2 & $01 p 36.22$ & 1 & 1.02 & 1.24 & 1.3 \\
\hline PTAFR & 01 p35-p34.3 & 1.24 & 1.01 & 0.57 & 0.55 \\
\hline FAF1 & 01 p33 & 1.2 & 1.01 & 0.53 & 0.52 \\
\hline PPAP2B & 01 pter-p22.1 & 0.31 & 0.26 & 0.59 & 0.57 \\
\hline$C Y P 2 J 2$ & 01 p31.3-p31.2 & 1.28 & 1.04 & 0.52 & 0.54 \\
\hline LPHN2 & $01 p 31.1$ & 1.16 & 0.98 & 0.57 & 0.53 \\
\hline GTF2B & 01 p22-p21 & 1.1 & 0.89 & 0.59 & 0.59 \\
\hline DPYD & 01 p22 & 0.21 & 0.15 & 0.59 & 0.54 \\
\hline NRAS & $01 p 13.2$ & 0.83 & 0.64 & 0.63 & 0.57 \\
\hline LMNA & $01 q 22$ & 1.18 & 0.91 & 1 & 1.05 \\
\hline CRB1 & $01 q 31.3$ & 0.74 & 0.4 & 0.88 & 0.88 \\
\hline TNNT2 & $01 q 32.1$ & 1.03 & 0.96 & 0.74 & 0.73 \\
\hline SMARCA4 & 19p13.2 & 1.06 & 1.08 & 1.3 & 1.39 \\
\hline$L D L R$ & 19p13.3 & 1.17 & 1.02 & 1.04 & 1.04 \\
\hline CCNE1 & $19 q 12$ & 0.88 & 0.81 & 0.57 & 0.58 \\
\hline PDCD5 & $19 q 12-q 13.1$ & 0.2 & 0.19 & 0.52 & 0.5 \\
\hline UPK1A & $19 q 13.13$ & 1.14 & 0.79 & 0.62 & 0.58 \\
\hline TGFB1 & $19 q 13.1$ & 0.95 & 0.83 & 0.53 & 0.5 \\
\hline PPP1R15A & $19 q 13.2$ & 0.67 & 0.42 & 0.6 & 0.57 \\
\hline$B A X$ & $19 q 13.3-q 13.4$ & 0.5 & 0.36 & 0.58 & 0.58 \\
\hline CHMP2A & $19 q 13.43$ & 0.97 & 0.85 & 0.54 & 0.53 \\
\hline Control & $02 \mathrm{p} 16$ & 1.16 & 1.14 & 1.04 & 1.07 \\
\hline Control & $03 p 25.3$ & 1.35 & 1.15 & 0.88 & 0.83 \\
\hline Control & $03 q$ & 1.07 & 1.02 & 1.06 & 1.05 \\
\hline Control & $05 q 22$ & 1.24 & 1.13 & 0.86 & 0.85 \\
\hline Control & $08 q$ & 0.89 & 0.66 & 0.95 & 1 \\
\hline Control & $08 q 13$ & 1.23 & 0.98 & 1 & 1.01 \\
\hline Control & $09 q 21$ & 1.07 & 1.08 & 1.3 & 1.39 \\
\hline Control & $11 q 23$ & 1.34 & 1.09 & 1.05 & 1 \\
\hline Control & $13 q 14.3$ & 0.99 & 1 & 1.22 & 1.27 \\
\hline Control & $14 q$ & 0.94 & 0.91 & 1 & 1 \\
\hline Control & $14 q 22$ & 0.99 & 1.01 & 1.23 & 1.28 \\
\hline Control & $15 q 21.1$ & 1 & 0.98 & 0.56 & 0.56 \\
\hline Control & $17 q 11.2$ & 0.88 & 0.63 & 0.89 & 0.92 \\
\hline Control & $17 q 21$ & 0.98 & 1 & 1.22 & 1.27 \\
\hline
\end{tabular}

Genes are named by their official symbol. P correspond to the pediatric glioma of study and PC to an oligodendroglioma with known 1p/19q codeletion (positive control). Number are the values obtained by Coffalyser analysis, normalized with DNA from 4 healthy volunteers (references). Bold style represents total marker loss and italics Loss of Heterozygosity.

\section{Postoperative course}

The patient's postoperative recovery was uneventful. There was a dramatic improvement in his symptoms in the immediate postoperative period with virtual cessation of the tremors. The initial follow-up using $3 \mathrm{~T}-\mathrm{MR}$ images obtained 1 month after the surgery showed a GTR of the tumor and no hydrocephalus. After the initial follow-up, the child was treated with radiotherapy and chemotherapy. An MR image obtained 9 months later revealed no tumor recurrence, and the patient remained neurologically intact (Figure 1B). No changes have been observed after 2 years of follow-up.

\section{Anatomical pathology}

Tumor proliferation consisted of round to slightly elongated and densely packed cells with round or ovoid hyper-chromatic nuclei and scarce cytoplasm, occasionally expressed as perinuclear halos but without a characteristic honeycomb pattern. Micro-calcifications were present but there was no necrosis (Figure 2A). A prominent microvascular stroma presenting branching capillaries with endothelial tumefaction was observed (Figure 2B). Most tumor cells had an anaplastic aspect with a high nuclear to cytoplasmic ratio, and mitosis were present (Figure 2C). However, intermingled "fried-egg" cells were observed in a number of anaplastic foci (Figure 2D). GFAP immunoreactivity was variable whereas Synaptophysin was negative (Figure 3A). Cytoplasmic immunoreactivity for Vimentin and CD57 (HNK-1) were positive (Figure 3B), and. nuclear p53 was positive in $15 \%-20 \%$ of cells (Figure 3C). The growth fraction (ki 67) was approximately $30 \%$ (Figure 3D).

The pathology diagnosis was anaplastic glioma, although a $1 \mathrm{p} / 19 \mathrm{q}$ analysis was suggested to obtain clues as to the presence of a possible oligodendroglial component. The unconventional microscopic pattern and the infrequent presentation of oligodendrogliomas in pediatric patients $[2,3]$ could, however, justify our generic diagnosis.

\section{Methods}

\section{Samples and DNA preparation}

Samples and clinical-pathological data were obtained according to the hospital ethics committee procedures. DNA was isolated from frozen tumor and peripheral blood using the Wizard Genomic DNA purification kit (Promega). DNA from an oligodendroglioma with known $1 \mathrm{p} / 19 \mathrm{q}$ loss was used as a positive control, and DNA from four healthy volunteers were used as references for multiplex ligation-dependent probe amplification (MLPA) reactions.

\section{Multiplex ligation-dependent probe amplification (MLPA) analysis}

MLPA is a technique by which up to 45 different sequences corresponding to specific known genes (or genomic regions) 


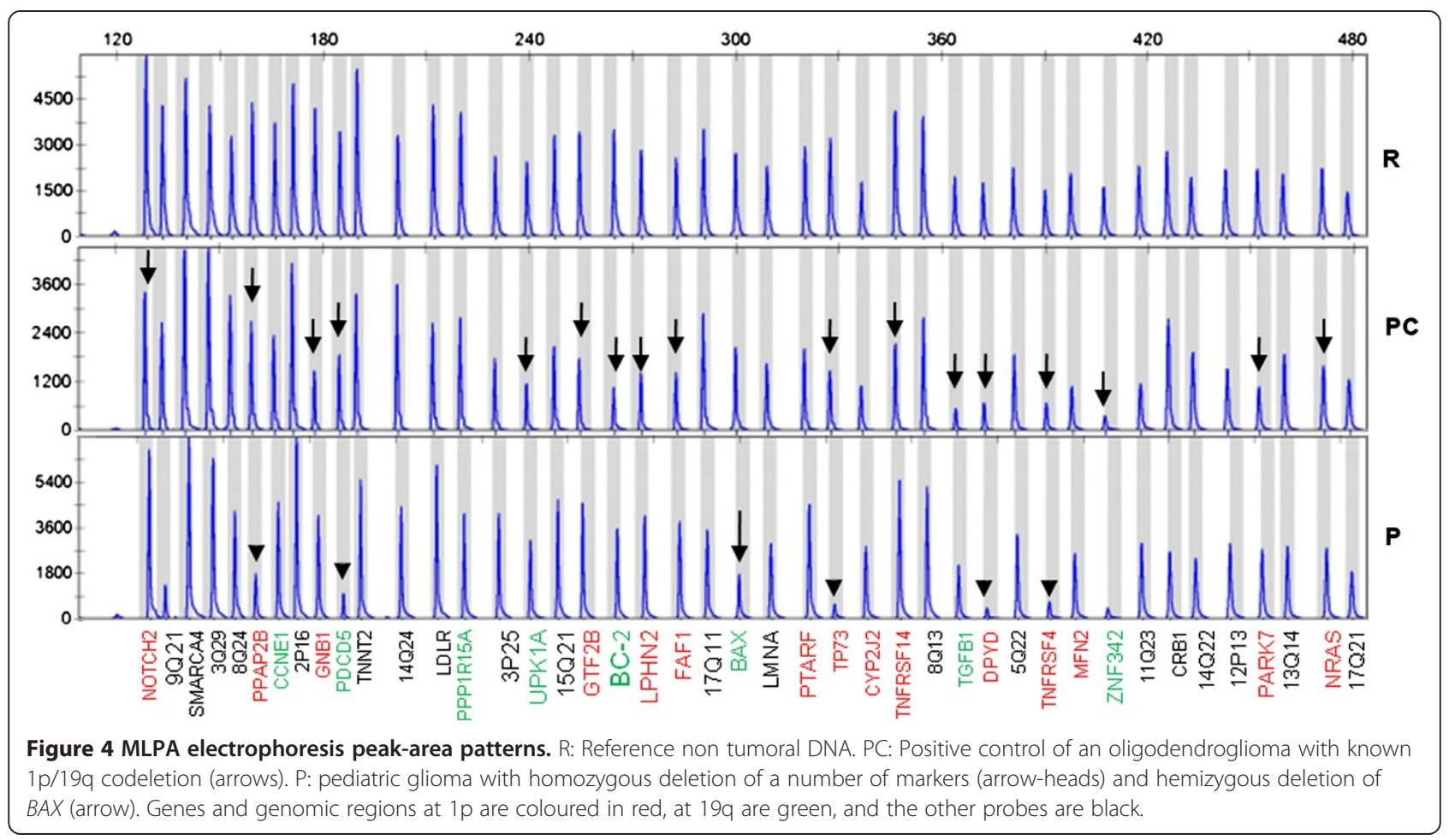

can be targeted in a single, semi-quantitative polymerase chain reaction (PCR)-based experiment [11]. The sequences detected can be small ( 60 nucleotides), enabling analysis of fragmented DNA. We used the MLPA SALSA P088-B1 kit (MRC-Holland, Amsterdam, Netherlands), which contains $151 \mathrm{p}$ probes, eight 19q probes, and 20 control probes specific to other chromosomes, including three 1q probes and two 19p probes. Information regarding the probe sequences and ligation sites can be found at www.mlpa.com. MLPA analysis was performed as described previously [12,13]. In brief, we used $100 \mathrm{ng}$ for each normal DNA controls and tumor sample. DNA denaturation and hybridization of the SALSA probes was followed by a ligation reaction and PCR. One microliter of the amplified sample product was analyzed using the ABI 3100 Avant sequencer (Applied Biosystems) using the ROX-500 Genescan (ABI 401734) as an internal size standard. Duplicate experiments were performed to obtain accurate MLPA values (Table 1). Data analysis was performed with MRC-Coffalyser version 9.4 software (MRC-Holland, Amsterdam, Netherlands). Successful ligation reaction and identification of samples with insufficient amounts of DNA were verified using MLPA's internal ligation-independent probes. Normalization for tumor data (including positive control oligodendroglioma and pediatric patient sample), was performed on the average of the four references probes. Single regression for references and tumor data slope correction was performed. Given that a value of 1 corresponds to a normal allele constitution,
$\mathrm{LOH}$ ratio limit was set at $<0.67$, homozygous loss at $<0.34$, and gains at $>1.3$. Probes were considered as altered only when duplicated runs corresponded to the same pattern.

\section{Isocitrate dehydrogenase 1 and 2 (IDH1/2) mutation analysis}

The genomic regions spanning the R132 codon of IDH1 and R172 of IDH2 genes were amplified and sequenced with an ABI PRISM 3100 Genetic analyzer and Sequencing Analysis 5.1.1 software (Applied Biosystem, Foster City, CA, USA) using the primers and conditions described previously $[14,15]$.

\section{Results}

The study was performed in duplicate and five control samples were used: one corresponding to a known oligodendroglioma with proven $1 \mathrm{p} / 19 \mathrm{q}$ loss (positive control), and four non-tumoral DNAs (used as references for MLPA analysis). As shown in Figure 4 and Table 1, an almost complete absence of signal was identified in a few markers: TNFRSF4 (located at 1p36.33), TP73 (1p36.32), PPAP2B (1pter-p22), DPYD (1p21.3) and PDCD5 (19q13.12), suggesting that total loss of these genomic regions occurred in the pediatric tumor reported herein. In addition, heterozygotic loss of $B A X$ (19q13.3-q13.4) was present, and no mutations of IDH1/2 were identified. Probe for ZNF342 presented problems even in references and therefore, it was excluded 
Table 2 Biological process of altered genes identified by MLPA in pediatric glioma and of neighbour genes located in the critical deleted regions

\begin{tabular}{|c|c|c|c|c|}
\hline Gene & Biological process & Chromosomal region & Neighbor genes & Biological process \\
\hline \multirow[t]{3}{*}{ TNFRSF4 } & Inflammatory and immune response & $01 p 36$ & TNFRSF18 & Apoptosis \\
\hline & & & TTLL10 & Protein polyglycylation \\
\hline & & & SDF4 & UV protection \\
\hline \multirow[t]{6}{*}{ TP73 } & DNA damage response & $01 p 36.3$ & ARHGEF16 & Apoptosis \\
\hline & & & $L R R C 47$ & Translation \\
\hline & & & SMIM1 & \\
\hline & & & WRAP73 & \\
\hline & & & TPRG1L & Synapse \\
\hline & & & MEGF6 & Calcium ion binding \\
\hline \multirow[t]{2}{*}{ PPAP2B } & Blood vessel development & 01 pter-p22.1 & PRKAA2 & Protein phosphorylation \\
\hline & & & Clorf168 & \\
\hline DPYD & Purine base catabolic process & $01 p 22$ & PTBP2 & mRNA processing \\
\hline \multirow[t]{7}{*}{ PDCD5 } & Apoptosis & $19 q 12-q 13.1$ & ANKRD27 & Early endosome to late endosome transport \\
\hline & & & DPY19L3 & \\
\hline & & & CEP89 & \\
\hline & & & SLC7A9 & Protein complex assembly \\
\hline & & & TDRD12 & \\
\hline & & & NUDT19 & \\
\hline & & & RGS9BP & Negative regulation of signal transduction \\
\hline \multirow[t]{9}{*}{$B A X$} & Apoptosis & $19 q 13.3-q 13.4$ & FTOL & \\
\hline & & & NTN5 & \\
\hline & & & PP1R15A & Apoptosis \\
\hline & & & NUCB1 & \\
\hline & & & CD37 & Regulation of humoral immune response \\
\hline & & & PPFIA3 & Neurotransmitter secretion \\
\hline & & & $C G B$ & \\
\hline & & & TYS1 & Apoptosis \\
\hline & & & $\mathrm{DHDH}$ & \\
\hline
\end{tabular}

Only the most nearby protein-coding genes were selected.

from assay. Control probe $12 \mathrm{p} 13$ was also excluded because pediatric glioma and positive control showed a value of 0 . Finally, the tumor DNA displayed allelic loss involving the $9 q 21$ control marker, although this was not numerically confirmed (Table 1).

\section{Discussion and conclusions}

Pediatric gliomagenesis seems to follow different molecular pathways from adults. Concurrent deletion of $1 \mathrm{p}$ and $19 \mathrm{q}$ is the hallmark of adult oligodendrogliomas (identified in up to $80 \%$ of tumors) [16-18] and results from an unbalanced $\mathrm{t}(1 ; 19)$ (q10; p10) $[19,20]$. Assessment of allelic status at 1p and $19 q$ has been established as a key tool for the diagnosis, treatment and prognosis of adult oligodendrogliomas, given that tumors carrying the co-deletion usually have a more favorable response to conventional chemotherapy agents [21,22]. Similarly, MGMT aberrant promoter methylation has been proposed as potentially associated with chemosensitivity and prolonged survival [23,24]. IDH1 mutations present in most oligodendrogliomas, most astrocytic tumors and secondary glioblastomas have been associated with better overall survival and progression-free survival [15,25]. Aberrant promoter methylation has also been described [26] and up to three epigenetic oligodendroglioma groups with various clinical and biological features have been identified [27]. These neoplasms are characterized by inactivating mutations of $C I C$, concurrent with $I D H$ sequence changes and $1 \mathrm{p} / 19 \mathrm{q}$ deletions [28]. Oligodendrogliomas are less commonly present in children (1\%-3\% of pediatric CNS neoplasms) [3] and the available molecular data suggest that pediatric gliomas display molecular features that are slightly different 
from those present in adults $[1,7,8]$, such as no $I D H 1$ or TP53 mutations and positive for MGMT methylation. However, 1p/19q concurrent deletion appears rare, although it is present in oligodendrogliomas from older children (over 10 years of age) [29-31]. Correct identification of these molecular changes might be useful if a similar correlation with prognosis could be found in pediatric oligodendrogliomas. However no correlation between $1 \mathrm{p} / 19 \mathrm{q}$ deletion and increased survival has been described in a series of high grade malignant pediatric gliomas, most of which were classified as astrocytomas [32]. It is possible that the molecular implications of losses involving $1 \mathrm{p} / 19 \mathrm{q}$ in pediatric glial tumors (including oligodendroglial tumors) are different from those in adult cases, i.e., that different genes could be the targets of these alterations and thus no correlation with increased survival should be expected. Candidate genes at $1 \mathrm{p} / 19 \mathrm{q}$ have been investigated in the search for potential targets of that co-deletion, including $\mathrm{NOTCH}$, CDKN2C, RAD54, CITED4, CAMTA1, TP73, EMP3 and $P E G 3$, but no consistent mutation of these genes has been demonstrated [8,33-35]. The infrequent presentation of oligodendrogliomas in pediatric patients and the unconventional microscopic pattern observed in the case reported herein could justify the generic diagnosis (anaplastic glioma). However, a number of other microscopic features (capillary network, micro-calcifications, CD57 positivity) are consistent with the presence of an oligodendroglioma component. The molecular findings in this tumor, which demonstrate $1 \mathrm{p} / 19 \mathrm{q}$ co-deletion (including homozygosus deletion of a few markers) could also support an oligodendroglioma diagnosis, although these molecular alterations are rare in pediatric oligodendrogliomas [30]. The absence of IDH1 mutations also agrees with the data in pediatric gliomas, including oligodendrogliomas [36,37]. Recent reports have identified no IDH1 mutations with variable allelic constitutions for $1 \mathrm{p} / 19 \mathrm{q}$ (including co-deletion to no loss) in disseminated oligodendroglial-like leptomeningeal tumors in pediatric patients [38,39]. However, no apparent leptomeningeal involvement was evident in the case reported herein. Another report described an aggressive clinical phenotype (8-month overall survival) characterizing a pediatric glioblastoma with an oligodendroglioma component, displaying neither $I D H 1 / 2$ mutation nor $1 \mathrm{p} / 19 \mathrm{q}$ co-deletion [40], which was clearly different from the case reported here. In conclusion, a definitive histopathological diagnosis could not be clearly established, and the doubt remains about whether this tumour could be classified as displaying (or not) a true oligodendroglial component. However, the identification of homozygous deletion involving a number of $1 \mathrm{p} / 19 \mathrm{q}$ markers provides insights on genomic regions in these chromosome arms, where potential critical target genes, which could participate in the development of pediatric (oligodendro) gliomas, might be located. As shown in Table 2, several genes involved in interesting biological functions are located in the neighborhood of the homozygous deleted markers in the case reported here. Functional and/or mutational analyses of these neighbour genes would provide insights on potential new regulation pathways, perhaps non-randomly involved in the development of pediatric gliomas.

\section{Consent}

Written informed consent was obtained from the parents for publication of this case report. A copy of the written consent is available for review by the Editor-in-Chief of this journal. Also, the molecular studies were performed on anonymized samples provided to the Molecular NeuroOncogenetics laboratory (IdiPAZ).

\section{Competing interests}

The authors declare that they have no competing interests.

\section{Authors' contributions}

MT-M and CP-G performed MLPA analysis. BM performed IDH mutation studies. FC performed surgery and MG performed histo-pathological studies, and both of them collected the clinical data relative to this case. RRB, GRP and JSC provided tools for analysis and analyzed the findings. MT-M, BM and JAR analyzed the findings, drafted the paper and revised the manuscript for important intellectual content. All authors contributed to the finalizing of the manuscript. All authors read and approved the final manuscript.

\section{Acknowledgements}

This work is part of a research supported by grant PI10/1972, from Fondo de Investigaciones Sanitarias (FIS), Ministerio de Sanidad, Servicios Sociales e Igualdad, Spain.

\section{Author details}

${ }^{1}$ Molecular Neuro-oncogenetics Laboratory, Research Unit-Unidad de Investigación, Hospital Universitario La Paz, Paseo de la Castellana 261, 28046 Madrid, Spain. ${ }^{2}$ Department of Pediatric Neurosurgery, Hospital Universitario La Paz, Paseo de la Castellana 261, 28046 Madrid, Spain. ${ }^{3}$ Department of Pathology, Hospital Universitario La Paz, Paseo de la Castellana 261, 28046 Madrid, Spain. ${ }^{4}$ Institute of Biological Sciences, Human Cytogenetics Laboratory, Federal University of Para, R Augusto Correa 01, Belem, PA 66075-110, Brazil. ${ }^{5}$ Genetics and Molecular Biology Laboratory, Federal University of Piau, Avda Sao Sebastiao 2819, Parnaiba, PI 64202-020, Brazil. 'Brain Tumor Biology Unit, University of Navarra School of Sciences, Irunlarrea 1, 31008 Pamplona, Spain. ${ }^{7}$ Molecular Pathology Research Unit, Virgen de la Salud Hospital, Avda Barber 30, 45004 Toledo, Spain.

Received: 3 October 2013 Accepted: 11 December 2013

Published: 6 January 2014

\section{References}

1. Hargrave D: Pediatric high and low grade glioma: the impact of tumour biology on current and future therapy. Br J Neurosurgery 2009, 23:351-363.

2. Houben MP, Aben KK, Teepen JL, Schouten-van Meerten AY, Tijssen CC, van Dujin CM, Coebergh JW: Stable incidence of childhood and adult glioma in The Netherlands, 1989-2003. Acta Oncol 2006, 45:272-279.

3. Louis DN, Ohgaki H, Wiestler OD, Cavenee WK: WHO classification of tumours of the central nervous system. Lyon: IARC; 2007.

4. Louis DN, Ohgaki H, Wiestler OD, Cavenee WK, Burger PC, Jouvet A, Scheithauer BW, Kleihues P: The 2007 WHO classification of tumours of the central nervous system. Acta Neuropathol 2007, 114:97-109.

5. Masui K, Cloughesy TF, Mischel PS: Molecular pathology in adult high-grade gliomas: from molecular diagnosis to target therapies. Neuropathol Appl Neurobiol 2012, 38:271-291. 
6. Blesa D, Mollejo M, Ruano Y, de Lope AR, Fiaño C, Ribalta T, Garcia JF, Campos-Martin Y, Hernandez-Moneo JL, Cigudosa JC, Melendez B: Novel genomic alterations and mechanisms associated with tumor progression in oligodendroglioma and mixed oligoastrocytoma. J Neuropathol Exp Neurol 2009, 68:274-285.

7. Chen Y-H, Gutmann DH: The molecular and cell biology of pediatric low-grade gliomas. Oncogene 2013. in press.

8. Marko NF, Weil RJ: The molecular biology of WHO Grade II gliomas. Neurosurg Focus 2013, 34:E1.

9. Zhang J, Wu G, Miller CP, Tatevossian RG, Dalton JD, Tang B, Orisme W, Punchihewa C, Parker M, Qaddoumi I, Boop FA, Lu C, Kandoth C, Ding L, Lee R, Huether R, Chen X, Hedlund E, Nagahawatte P, Rusch M, Boggs K, Cheng J, Becksfort J, Ma J, Song G, Li Y, Wei L, Wang J, Shurtleff S, Easton J, et al: Whole-genome sequencing identifies genetic alterations in pediatric low-grade gliomas. Nat Genet 2013, 45:602-612.

10. Ramkissoon LA, Horowitz PM, Craig JM, Ramkissoon SH, Rich BE, Schumacher SE, McKenna A, Lawrence MS, Bergthold G, Brastianos PK, Tabak B, Ducar MD, et al: Genomic analysis of diffuse pediatric low-grade gliomas identifies recurrent oncogenic truncating rearrangements in the transcription factor MYBL1. Proc Natl Acad Sci U S A 2013, 110:8188-8193.

11. Schouten JP, McElgunn CJ, Waaijer R, Zwijnenburg D, Diepvens F, Pals G. Relative quantification of 40 nucleic acid sequences by multiplex ligation-dependent probe amplification. Nucleic Acids Res 2002, 30:e57.

12. Franco-Hernandez C, Martinez-Glez V, Alonso ME, de Campos JM, Isla A, Vaquero J, Gutierrez M, Rey JA: Gene dosage and mutational analyses of EGFR in oligodendrogliomas. Int J Oncology 2007, 30:209-215.

13. Franco-Hernandez C, Martinez-Glez V, de Campos JM, Isla A, Vaquero J, Gutierrez M, Casartelli C, Rey JA: Allelic status of $1 p$ and $19 q$ in oligodendrogliomas and glioblastomas: multiplex ligation-dependent probe amplification versus loss of heterozygosity. Cancer Genet Cytogenet 2009, 190:93-96.

14. Balss J, Meyer J, Mueller W, Korshunov A, Hartmann C, von Deimling A: Analysis of the IDH1 codon 132 mutation in brain tumors. Acta Neuropathol 2008, 116:597-602.

15. Hartmann C, Meyer J, Balss J, Capper D, Mueller W, Christians A, Felsberg J, Wolter M, Mawrin C, Wick W, Weller M, Herold-Mende C, Unterberg A Jeuken JWM, Wesseling P, Reifenberger G, von Deimling A: Type and frequency of $I D H 1$ and $I D H 2$ mutations are related to astrocytic and oligodendroglial differentiation and age: a study of 1.010 diffuse gliomas. Acta Neuropathol 2009, 118:469-474

16. Reifenberger J, Reifenberger G, Liu L, James CD, Wechsler W, Collins VP: Molecular genetic analysis of oligodendroglial tumors shows preferential allelic deletions on 19q and 1p. Am J Pathol 1994, 145:1175-1190.

17. Bello MJ, Leone PE, Vaquero J, de Campos JM, Kusak ME, Sarasa JL, Pestaña A Rey JA: Allelic loss at $1 p$ and $19 q$ frequently occurs in association and may represent early oncogenic events in oligodendroglial tumors. Int J Cancer 1995, 64:207-210.

18. Kraus JA, Koopmann J, Kaskel P, Maintz D, Brandner S, Schramm J, Louis DN, Wiestler OD, von Deimling A: Shared allelic losses on chromosomes 1p and $19 q$ suggest a common origin of oligodendroglioma and oligoastrocytoma. J Neuropathol Exp Neurol 1995, 54:91-95.

19. Griffin $C A$, Burger $P$, Marsberger $L$, Yonescu $R$, Swierczynski S, Weingart JD, Murphy KM: Identification of der $(1 ; 19)(q 10 ; p 10)$ in five oligodendrogliomas suggests mechanism of concurrent $1 p$ and $19 q$ loss. J Neuropathol Exp Neurol 2006, 65:988-994.

20. Jenkins RB, Blair H, Ballman KV, Giannini C, Arusell RM, Law M, Flynn H, Passe S, Felten S, Brown PD, Shaw EG, Buckner JC: A t $(1 ; 19)(q 10 ; p 10)$ mediates the combined deletions of $1 p$ and $19 q$ and predicts a better prognosis of patients with oligodendroglioma. Cancer Res 2006, 66:9852-9861

21. Cairncross JG, Ueki K, Zlatescu C, Lisle DK, Finkelstein DM, Hammond RR, Silver JS, Stark PC, Macdonald DR, Ino Y, Ramsay DA, Louis DN: Specific genetic predictors of chemotherapeutic response and survival in patients with anaplastic oligodendroglioma. J Natl Cancer Inst 1998, 90:1473-1479.

22. Weller M, Berger H, Hartmann C, Schramm J, Westphal M, Simon M, Goldbrunner R, Krex D, Steinbach JP, Ostertag CB, Loeffler M, Pietsch T, von D: Combined 1p/19q loss in oligodendroglial tumors: predictive or prognostic biomarker. Clin Cancer Res 2007, 13:6933-6937.

23. Brandes AA, Tosoni A, Cavallo G, Reni M, Franceschi E, Bonaldi L, Bertorelle R, Gardiman M, Ghimenton C, Iuzzolino P, Pession A, Blatt V, Ermani M: Correlations between O6-methylguanine DNA methyltransferase promoter methylation status, $1 p$ and $19 q$ deletions, and response to temozolomide in anaplastic and recurrent oligodendroglioma: a prospective GICNO study. J Clin Oncol 2006, 24:4746-4753.

24. Levin N, Lavon I, Zelikovitsh B, Fuchs D, Bokstein F, Fellig Y, Siegal T: Progressive low-grade oligodendrogliomas: response to temozolomide and correlation between genetic profile and $0^{6}$-methylguanine DNA methyltransferase protein expression. Cancer 2006, 106:1759-1765.

25. von Deimling A, Korshunov A, Hartmannn C: The next generation of glioma biomarkers: MGMT methylation, BRAF fusions and IDH1 mutations. Brain Pathol 2011, 21:74-87.

26. Alonso ME, Bello MJ, Gonzalez-Gomez P, Arjona D, Lomas J, de Campos JM, Isla A Sarasa JL, Rey JA: Aberrant promoter methylation of multiple genes in oligodendrogliomas and ependymomas. Cancer Genet Cytogenet 2003, 144:134-142.

27. Mur P, Mollejo M, Ruano Y, Rodriguez de Lope A, Fiaño C, Garcia JF, Castresana JS, Hernandez-Lain A, Rey JA, Melendez B: Codeletion of 1p and $19 q$ determines distinct gene methylation and expression profiles in IDH-mutated oligodendroglial tumors. Acta Neurpathol 2013, 126:277-289.

28. Yip S, Butterfield YS, Morozova O, Chittaranjan S, Blough MD, An J, Birol I, Chesnelong C, Chiu R, Chuah E, Corbett R, Docking R, Firme M, Hirst M, Jackman S, Karsan A, Li H, Louis DN, Maslova A, Moore R, Moradian A, Mungall KL, Perizzolo M, Qian J, Roldan G, Smith EE, Tamura-Wells J, Thiessen N, Varhol R, Weiss $S$, et al: Concurrent CIC mutations, IDH mutations, and $1 p / 19 q$ loss distinguish oligodendrogliomas from other cancers. J Pathol 2012, 226:7-16.

29. Myal Y, del Bigio MR, Rhodes RH: Age-related differences in $1 p$ and $19 q$ deletions in oligodendrogliomas. BMC Clin Pathol 2003, 3:6.

30. Kreiger PA, Okada Y, Simon S, Rorke LB, Louis DN, Golden JA: Losses of chromosomes $1 p$ and $19 q$ are rare in pediatric oligodendrogliomas. Acta Neuropathol 2005, 109:387-392.

31. Suri $V$, Jha $P$, Agarwal S, Pathak $P$, Sharma MC, Sharma V, Shukla S, Somasundaram K, Mahapatra AK, Kale SS, Sarkar C: Molecular profile of oligodendrogliomas in young patients. Neuro Oncol 2011, 13:1099-1106.

32. Pollak IF, Finkelstein SD, Burnham J, Hamilton RL, Yates AJ, Holmes EJ, Boyett JM, Finlay JL: Association between chromosome 1p and 19q loss and outcome in pediatric malignant gliomas: results from the CCG-945 cohort. Pediatr Neurosurg 2003, 39:114-121.

33. Bello MJ, de Campos JM, Vaquero J, Ruiz-Barnes P, Kusak ME, Sarasa JL, Rey JA: hRAD54 gene and $1 \mathrm{p}$ high-resolution deletion-mapping analyses in oligodendrogliomas. Cancer Genet Cytogenet 2000, 116:142-147.

34. Alonso ME, Bello MJ, Gonzalez-Gomez P, Lomas J, Arjona D, de Campos JM, Kusak ME, Sarasa JL, Isla A, Rey JA: Mutation analysis of the $p 73$ gene in nonastrocytic brain tumors. Br J Cancer 2001, 85:204-208.

35. Alonso ME, Bello MJ, Arjona D, Gonzalez-Gomez P, Amiñoso C, Lopez-Marin I, de Campos JM, Isla A, Vaquero J, Gutierrez M, Sarasa JL, Rey JA: Mutational study of the $1 p$ located genes $p 18^{\text {ink } 4 c}$, Patched-2, RIZ1 and KIF1B in oligodendrogliomas. Oncology Rep 2005, 13:539-542.

36. Capper D, Reuss D, Schittenhelm C, Hartmann C, Bremer J, Sahm F, Harter PN Jeibmann A, von Deimling A: Mutation-specific IDH1 antibody differentiates oligodendrogliomas and oligoastrocytomas from other brain tumors with oligodendroglioma-like component. Acta Neuropathol 2011, 121:241-252.

37. Buccoliero AM, Castiglione F, Degl'Innocenti DR, Gheri CF, Genitori L, Taddei GL: IDH1 mutation in pediatric gliomas: has it a diagnostic and prognostic value? Fetal Pediatr Pathol 2012, 31:278-282.

38. Rodriguez FJ, Perry A, Rosenblum MK, Krawitz S, Cohen KJ, Lin D, Mosier S, Lin MT, Eberhart CG, Burger PC: Disseminated oligodendroglial-like leptomeningeal tumor of childhood: a distinctive clinicopathological entity. Acta Neuropathol 2012, 124:627-641.

39. Schneiderjan MJ, Alghamdi S, Castellano-Sanchez A, Mazewski C, Brahma B, Brat DJ, Brathwaite CD, Janss AJ: Difusse leptomeningeal neuroepithelis tumor: 9 pediatric cases with chromosome $1 p / 19 q$ deletion status and IDH1 (R132H) immunohistochemistry. Am J Surg Pathol 2013, 37:763-771.

40. Mizoguchi M, Hata N, Suzuki SO, Fujioka Y, Murata H, Amano T, Nakamizo A, Yoshimoto K, Iwaki T, Sasaki T: Pediatric glioblastoma with oligodendroglioma component: aggressive clinical phenotype with distinct molecular characteristics. Neuropathology 2013, 33:652-657.

doi:10.1186/1755-8166-7-1

Cite this article as: Torres-Martín et al:: Homozygous deletion of TNFRSF4, TP73, PPAP2B and DPYD at $1 p$ and PDCD 5 at $19 q$ identified by multiplex ligation-dependent probe amplification (MLPA) analysis in pediatric anaplastic glioma with questionable oligodendroglial component. Molecular Cytogenetics 2014 7:1. 